\title{
Effects of Group Psychotherapy in College Students: A Six and Twelve Month Evaluation Comparison
}

\author{
Juan Antonio Mejías*, María Martina Jurado, Silvia Araceli Tafoya, Lizbeth Beltrán \\ Psychiatry and Mental Health Department, Faculty of Medicine, National Autonomous University of Mexico, Mexico City, Mexico \\ Email address: \\ jamejviz@yahoo.com(J.A. Mejías), idamar007@gmail.com(M. M. Jurado), stafoya@unam.mx (S. A. Tafoya), \\ lizmed23@gmail.com(L. Beltrán) \\ ${ }^{*}$ Corresponding author
}

\section{To cite this article:}

Juan Antonio Mejías, María Martina Jurado, Silvia Araceli Tafoya, Lizbeth Beltrán. Effects of Group Psychotherapy in College Students: A Six and Twelve Month Evaluation Comparison. American Journal of Applied Psychology. Vol. 7, No. 1, 2018, pp. 21-28.

doi: 10.11648/j.ajap.20180701.14

Received: February 13, 2018; Accepted: March 16, 2018; Published: April 9, 2018

\begin{abstract}
Group psychotherapy expects to afford more lasting changes on patients' symptomatology, as well as reinforce positive aspects of self-esteem and social adjustment. However, few investigations show the effects over an extended period of intervention. This study aimed to assess changes in symptoms of anxiety, depression, self-esteem and social adjustment within a period of six and twelve months in college students who attended interactional group psychotherapy. A longitudinal study was carried out with college students who attended group psychotherapy, using the database of forty-one of the students who stayed for six months and 23 of them, for 12 months. Significant improvements were observed at 6 and 12 months in anxietystate and depressive symptoms compared to baseline data, but there were no changes between 6 and 12 months. The comparison between well-being aspects such as self-esteem and social adaptation showed improvements mostly, up to 12 months, without any significant changes between 6 and 12 months. Also, there was observed a correlation between well-being punctuations (self-esteem and social adaptation) and the decrease of depressive and anxiety symptomatology. Long-term group psychotherapy demonstrates a decrease of symptomatology at six months of intervention, and they remain at 12 months; however, other aspects of patient's well-being, are enhanced to a higher level until 12 months.
\end{abstract}

Keywords: Group Psychotherapy, College Students, Anxiety, Depression, Self-Esteem, Social Adaptation

\section{Introduction}

It has been observed that group psychotherapy represents a useful therapeutic option to improve depressive and anxious symptoms, not only because it may offer a small amount of clinical savings throughout an academic year [1], but also because of the long-term improvements it can provide [2]. Besides, there is evidence about its effect on self-esteem and social adjustment. However, there are fewer trials which quantitatively evaluate these changes; therefore, it is necessary to measure the impact that it may have on these variables over time.

Within the previous publications about group psychotherapy, Eisenberg in 2007 and Ghodasara in 2011 [3, 4] described information about group therapy theory and practice, including aspects that can be studied with this type of approach. Nevertheless, less evaluate the changes observed in the participants using known and valid instruments. On the other hand, there are studies of groups in which the approach is brief, where schematic and delimited parameters of the type of therapeutic approach and specific problems handled are established, with short-term results, in several sessions [5].

There are less reported trials with a long-term interactional approach where patients with neurotic problems (depression, anxiety, non-serious personality disorders), and difficulties in their social performance, and low self-esteem are treated.

This type of therapies affects their academic achievement, as it has been observed in groups that have formed in psychological or psychiatric care centers in different schools or universities [6]. Long-term evaluations with interactional psychotherapies using valid instruments in individual therapy are also scarce. There are two meta-analyses which indicate 
that long-term interactional therapy offers an advantage for the treatment of personality disorders and complex mental conditions, compared to short-term therapies [7,8].

Mental illnesses in university students represent a significant problem for educational institutes. According to the results of a survey conducted by Eisenberg et al., in university students, considerable data on the prevalence of depression and anxiety disorders was found, as well as the presence of suicidal ideation through the course of these illnesses. They found that among undergraduate students, depression reached a $15.6 \%$ and a $13.3 \%$ of postgraduate students [3].

Reference [9] carried out a trial in 2005 in a Mexican population, analyzing the prevalence of depression in a group of adults (from 18 to 65 years old). They found that the percentage of women who had depressive symptoms was about $5.8 \%(\mathrm{CI} 95 \%=5.2,6.5)$, and $2.5 \%$ in men (CI 95\% $=2.2$, 3.0). This prevalence is consistently maintained among men and women, independently from the age group studied.

There are no recent studies about depression and anxiety in Mexican university students. However, in 1995, Rocha \& Ortega-Soto [10] evaluated its prevalence in a random sample of 1026 undergraduate students from one of the campuses of the National Autonomous University of Mexico (UNAM), using the Beck's Depression Inventory with a cut-off point of 14 and finding that $11.8 \%$ had depressive symptoms.

On the other hand, more information has been reported in recent studies of universities from other countries. Authors like Balanza-Galindo, Morales-Moreno, \& Guerrero-Muñoz [11] in the year of 2009 in Spain, found a high incidence of depressive and anxious symptoms in 700 college students using the Goldberg Anxiety and Depression Scale (GADS), with a prevalence of $47.1 \%$ for anxiety and $55.6 \%$ for depression, with a higher risk for women. In another study in Peru in the year of 2007, Riveros, Hernández, \& Rivera [12], in a random sample of 500 students from different careers, found $15.35 \%$ (mild depression) and 2.30\% (moderate depression) in women, vs. 5.30\% (mild depression) and $2.30 \%$ (moderate depression) in men. The scale applied was the Hospital Anxiety and Depression Scale (HADS).

Reference $[3,13]$ focused their research on describing the factors that may be related to the appearance or perpetuation of psychiatric conditions, to know more about the phenomenon of mental health issues students may face.

However, mental health should be considered in its broadest meaning, that is, not only as the lack of disease, but as the complete well-being of the individual [14]. Reference [15] found that concretely, throughout the process of group psychotherapy, it is observed that patients change some aspects of their lifestyle, self-image, relationships, behavior and even the control of diverse symptoms.

Some authors like Ghodasara, S. L., Davidson, M. A., Reich, M. S., Savoie, C. V., \& Rodgers, S. M. [4] implemented group approaches in a large number of determined pathologic situations with specific objectives. For instance, in group psychotherapy for non-psychotic patients, who have mild to moderate mood or affective disorders, named as "non-hospitalized" by Yalom, objectives are less specific. However, the desired changes are constant in areas such as improving self-esteem, improving interpersonal relationships and an adequate balance in the subject's affective state [16].

Reference [17] proposed a way to evaluate the patient's change as the result of group psychotherapy, considering for that outcome the symptoms and the social functionality, suggesting the use of self-evaluating scales and other instruments applied by the therapist.

Another trial evaluated the changes in group therapy, measuring the intensity of depression, stress, low ability to cope with problems and other stressful feelings, founding that in early stages of psychotherapy there is a "deterioration" and afterward, an improvement [18]. Similarly, Dick \& Wooff in 1986 [19], in groups seen in 12 sessions with a dynamic group psychotherapy program, determined that a year after therapy, the majority $(85 \%)$ decreased their dependence to psychiatric services and showed a considerable change regarding their self-satisfaction, reflected on an attitudinal questionnaire.

Reference [20] applied the Coopersmith Self-Esteem Inventory at different times through therapy, concluding that patients showed a statistically significant improvement in their self-esteem, throughout a psychodynamic group psychotherapy approach.

In another trial in 2008, Soleymani M., Mohammad, K. P., \& Doulatshahi, B. [21] investigated the effectiveness of brief group interpersonal psychotherapy in reducing depressive symptoms, as well as in attributional style and dysfunctional attitudes. Participants were 25 university students who scored 14 or higher on the Beck Depression Inventory-II. They were randomly assigned to two groups: 12 participants to the experimental group and 13 to the control group. All of them completed the Attributional Style Questionnaire and the Dysfunctional Attitudes Scale. The control group was placed on a waiting list; meanwhile, the experimental group participated for 8 sessions of psychotherapy to decrease depressive symptoms as well as dysfunctional attitudes. Results showed that depressive symptoms decreased, but there were no changes reflected on the Attributional Style Questionnaire.

Some authors point out that diagnostic and symptoms severity scales, neurophysiological tests or projective test can be used to assess the role of group psychotherapy in university students who receive treatment for major depressive disorder or anxiety disorders because information about it is still limited. Also, the presence of psychopathology and some aspects of the personality and mental functionality can be determined [22].

In this way, there is relevant evidence that points out that the combination of a psychotherapeutic process with pharmacological treatment in a mental disorder may have a positive effect on the results; this is particularly true for depressive disorders treated along with group psychotherapy [23, 24].

The investigation carried out by Mejías J. A., Jurado, M. M., Winckelmann, R., \& Tafoya, S. A [15] assessed the changes of a Yalom type group psychotherapy in university 
outpatients over a year, where 3 groups were formed. Some of the patients had pharmacological treatment (to control depressive symptomatology) besides group therapy, proving the advantages of this combination.

Reference [13] focused on the association of social factors with the presence of psychopathology in university students, pointing out that the most prevalent mental disorders in female college students were major depressive disorder, generalized anxiety disorder, and nicotine dependence. These were associated with social factors such as family income, students' economic independence, type of academic discipline, domestic violence, social support networks, and self-esteem.

\section{Objective}

This study aims to estimate the changes in anxious and depressive symptomatology, self-esteem and social adaptation in university patients who attended long-term group psychotherapy. Evaluations were applied at study entry, at six and 12 months, comparing the six months results against 12 months results.

\section{Methods}

\subsection{Design}

Quasi-experimental, prospective, longitudinal study

\subsection{Participants}

Patients who received group therapy were university students between 17 and 27 years old, at the Mental Health Clinic of the Faculty of Medicine, UNAM, who attended for treatment due to different problems (mood, anxiety or mild personality disorders). They were previously diagnosed and in some cases pharmacologically treated until they were stabilized in the acute phase so that afterward they could join group psychotherapy.

Since it was a long-term group, participants were asked to commit for at least a year. For this trial, patients who completed the six and twelve months of evaluation were considered. Initially, 48 students were contemplated, seven students left before completing six months and only 23 stayed for 12 months.

\subsection{Procedure}

Groups were formed by students who required psychiatric attention in the Psychiatry and Mental Health Department from 2013 to 2016. For their admission, students voluntarily attended the clinic due to presenting mostly anxiousdepressive symptomatology, being evaluated by a Psychiatrist, who established the diagnosis and pharmacological treatment if necessary. After the acute symptomatology was controlled, possible candidates for group psychotherapy were assessed for at least three sessions, to establish the appropriateness of their admission. Patients signed an informed consent form for their participation and were notified of a consent revocation format, in case they wanted to leave the study. At that time, the first evaluation was applied and repeated six and 12 months later.

Patients were treated in interactional groups, led by two therapists with more than 25 years of experience in this type of psychotherapy, in weekly sessions of two hours each, for at least 12 months. Each group was composed of an average of 10 patients.

The Patient Health Questionnaire (PHQ9) and State-Trait Anxiety Inventory (STAI) were used to evaluate Depression and anxiety, at study entry, six and twelve months later. Selfesteem and social adjustment were also assessed during these periods, applying the Rosenberg questionnaire and Coopersmith Self-Esteem Inventories for adults and the Social Adaptation Self-evaluation Scale (SASS), respectively.

Patients that were not able to be part of group therapy were seen in individual therapy, once a month and received pharmacological treatment, in case they required it.

\subsection{Instruments}

Patient Health Questionnaire (PHQ-9): evaluates depressive symptoms in a self-applicable form. It has nine items based on the criteria for major depressive disorder according to the Diagnostic and Statistical Manual of Mental Disorders (DSMIV). It helps to determine the diagnosis and severity of the symptoms. The last item has proven to be a useful measure of global functioning concerning depressive symptoms. The time frame references are the past two weeks. The subject evaluates each question with a scale which goes from $0=$ Not at all, $1=$ several days, $2=$ More than half of the days and $3=$ Nearly every day. Its clinimetric properties were assessed in Chilean population in first attention level, and it was found to have a sensitivity of $92 \%$ and a specificity of $89 \%$ for the diagnosis of major depressive disorder [25]. Sensitivity to change has been evaluated in a brief report with three groups of patients whose depression status improved, remained or deteriorated over time, and were followed up for about a year. They completed the PHQ-9 and the Structured Clinical Interview for DSM-IV (SCID) at baseline and follow-up. Using Effect sizes, they demonstrated that PHQ-9 possesses the ability to detect depression outcome and changes over time, making it a useful tool to monitor depression treatment [26].

State-Trait Anxiety Inventory (STAI): it is a selfadministered instrument for the clinic and general population that evaluates anxiety based on its clinical manifestation according to the concepts of "state," defined as a transient emotion, and "trait" as a relatively stable trend. It is composed of 40 items, 20 for each of the two subscales, and having the present moment as the time frame for the first and most of the occasions for the second. There are no cut-off points. The final grade is transformed to centiles according to gender and age. Both subscales have reported internal consistency indexes of up to 0.92 . In a sample of 1036 adults, a reliable analysis was performed using the Cronbach's alfa (0.90 for anxiety trait and 0.94 for anxiety state) [27]. Under different experimental conditions, Silva et al., obtained a high test-retest reliability between 0.73 and 0.86 regarding STAI-trait, due to the relative stability over time. By the other hand, the stability on the STAI-state tends to be lower, 
because situational factors influence it at a particular moment; that is why the obtained results varied between 0.16 and 0.54 [28]. The STAI Trait has evidenced excellent test-retest reliability (average $\mathrm{r}=.88$ ) at multiple time intervals [29].

Coopersmith Self-Esteem Inventory (adult version): quantitative self-esteem measurement instrument. It consists of 25 statements with dichotomous answers. This instrument was developed based on the 58 questions inventory for children. Lara-Cantú et al. tested its validity and reliability in a sample of 411 Mexicans. They reported a Cronbach's alfa of 0.81 and appropriate behavior for each of the statements [30].

Rosenberg self-esteem scale: it consists of 10 items and is self-administered. The patient responds according to Guttmanlike scale. Answers to questions 1, 3, 4, 7 and 10 are rated inversed. Authors do not recommend a specific cut-off point. The result ranges from 10 to 40 points, meaning that higher scores indicate higher self-esteem. Its clinimetric properties have demonstrated a reproducibility coefficient of 0.92 , which reflects its adequate internal consistency and good stability results with correlations of 0.85 and 0.88 in test-retest. It has shown concurrent, predictive and construct validity [31].

Social Adaptation Self-evaluation Scale (SASS): it evaluates patient's perception of their level of social adaptation. It consists of 21 items, and it is self-administered. It explores the functioning in the following areas of life: Work, Family, Leisure, Relationships, and Motivations/interests. The patient responds using a Likert type scale with four levels of answers ranging from 0 (worst performance) to 3 (best performance). The time frame is the present moment. Cut-off points are $<25=$ social maladjustment, $25-55=$ normality, $>55=$ "pathological over adaptation." The instrument has demonstrated an internal structure with correlation coefficients of $>0.40$ and internal validity of 0.74 and construct validity [32].

\section{Statistical Analysis}

All analyses were performed by the IBM Statistical
Package for the Social Sciences (SPSS), Version 23 (SPSS Inc. 2014), and alpha was set at $p<.05$ for significance. Kolmogorov-Smirnov (K-S) tests were carried out to assess the normality of the data. For the statistical analysis Student's t-test and Chi-squared test were used when comparing groups of 6 and 12 months. Afterward, repeated measures ANOVA tests were performed, to assess changes over time, using Greenhouse-Geisser correction in case sphericity was not observed and Bonferroni test for post-hoc analysis.

\section{Results}

Initially, 48 university students requested attention at the Psychiatry and Mental Health Department, of which 7 (15\%) left the groups, $18(37 \%)$ remained only for 6 months, and 23 (48\%) completed 12 months. As it was demonstrated in a previous trial in this same population, there were no differences at baseline sociodemographic and clinical variables, except for age between those who left the therapy since the beginning and those who stayed [33].

Therefore, the sample of those who completed 6 months of evaluation was formed of 5 men and 13 women, with an average age of 22.3 years $(\mathrm{SD} \pm 1.9)$. Most of them were enrolled in a bachelor's degree (89\%) and with a low proportion of students who had pharmacological treatment besides to group psychotherapy (33\%). Patients who stayed for 12 months in therapy were 11 men and 12 women, with an average age of 22.5 ( $\mathrm{SD} \pm 2.0$ ). They were enrolled in a bachelor's degree (70\%), but with a mild increase of those who had pharmacological treatment (61\%) against the 6 months sample; however, this did not represent a significant difference (Table 1).

The principal type of problem why students attended group therapy were problems related to personal matters $(61 \%)$ as well as family situations $(22 \%)$ at six months. These problems were inverted at 12 months; for instance, $43 \%$ pointed out family situations and $30 \%$ personal matters, without any significant differences (Table 1).

Table 1. Comparison between groups who attended therapy for 6 months against those who attended 12 months.

\begin{tabular}{|c|c|c|c|c|c|}
\hline & \multicolumn{2}{|c|}{ Time in psychotherapy $f(\%)$} & \multirow{2}{*}{$\chi^{2}$} & \multirow{2}{*}{$\mathbf{p}$} & \multirow{2}{*}{ Total } \\
\hline & 6 months $(n=18)$ & 12 months $(n=23)$ & & & \\
\hline $\begin{array}{l}\text { Age (years)* } \\
\text { Gender }\end{array}$ & $22.3(1.9)$ & $22.5(2.0)$ & -0.30 & .765 & $22.4(2.0)$ \\
\hline Male & $5(28)$ & $11(48)$ & & & $16(39)$ \\
\hline $\begin{array}{l}\text { Female } \\
\text { Marital status }\end{array}$ & $13(72)$ & $12(52)$ & 1.71 & .192 & $25(61)$ \\
\hline Married/Civil union & 0 & $1(4)$ & & & $1(2)$ \\
\hline $\begin{array}{l}\text { Single } \\
\text { Education }\end{array}$ & $18(100)$ & $22(96)$ & 1.18 & .278 & $40(98)$ \\
\hline High school & $2(11)$ & $6(26)$ & & & $8(19)$ \\
\hline Bachelor's degree & $16(89)$ & $16(70)$ & & & $32(78)$ \\
\hline $\begin{array}{l}\text { Graduate } \\
\text { Lives with }\end{array}$ & 0 & $1(4)$ & 2.87 & .238 & $1(2)$ \\
\hline Alone & $2(11)$ & $4(17)$ & & & $6(15)$ \\
\hline Family & $15(83)$ & $18(78)$ & & & $33(81)$ \\
\hline Friends & 0 & $1(4)$ & & & $1(2)$ \\
\hline $\begin{array}{l}\text { Legal guardian } \\
\text { Pharmacological treatment }\end{array}$ & $1(6)$ & 0 & 3.11 & .374 & $1(2)$ \\
\hline No & $12(67)$ & $9(39)$ & & & $21(51)$ \\
\hline
\end{tabular}




\begin{tabular}{|c|c|c|c|c|c|}
\hline & \multicolumn{2}{|c|}{ Time in psychotherapy $f(\%)$} & \multirow{2}{*}{$\chi^{2}$} & \multirow{2}{*}{$\mathbf{p}$} & \multirow{2}{*}{ Total } \\
\hline & 6 months $(n=18)$ & 12 months $(n=23)$ & & & \\
\hline Yes & $6(33)$ & $14(61)$ & 3.06 & .080 & $20(49)$ \\
\hline Type of current problem & & & & & \\
\hline Family & $4(22)$ & $10(43)$ & & & $14(34)$ \\
\hline Personal & $11(61)$ & $7(30)$ & & & $18(44)$ \\
\hline Interpersonal relationship & $2(11)$ & $3(13)$ & & & $5(12)$ \\
\hline School & $1(6)$ & $3(13)$ & 4.19 & .242 & $4(10)$ \\
\hline
\end{tabular}

Significant improvement was found at 6 and 12 months in some of the symptomatology scales, in which post-hoc tests showed differences in the comparisons between baseline against 6 months and baseline vs. 12, but not when comparing 6 months vs. 12 .

Regarding anxiety, it was also observed that anxiety-trait $F_{(2)}=0.14, \mathrm{p}=.871$ (Figure 1B), as well as total anxiety $F_{(2)}=2.81, \mathrm{p}=.072$ (Figure 1A), demonstrated changes over time, although the last one tends to show enhancement. On the other hand, anxiety-state significantly decreased $F_{(2)}=10.23$, $\mathrm{p}=.0001$, showing changes from baseline data to 6 months $(\mathrm{p}=.002)$ and from baseline to 12 months $(\mathrm{p}=.012)$, but not when comparing 6 and 12 months $(p=.999)$ (Figure 1C).

Depressive symptoms also significantly decreased over time, $F_{(2)}=10.94, \mathrm{p}=.003$, showing changes from baseline to 6 months $(\mathrm{p}=.002)$ and from baseline to 12 months $(\mathrm{p}=.009)$, but not when comparing 6 and 12 months $(\mathrm{p}=.962)$ (Figure 1D).
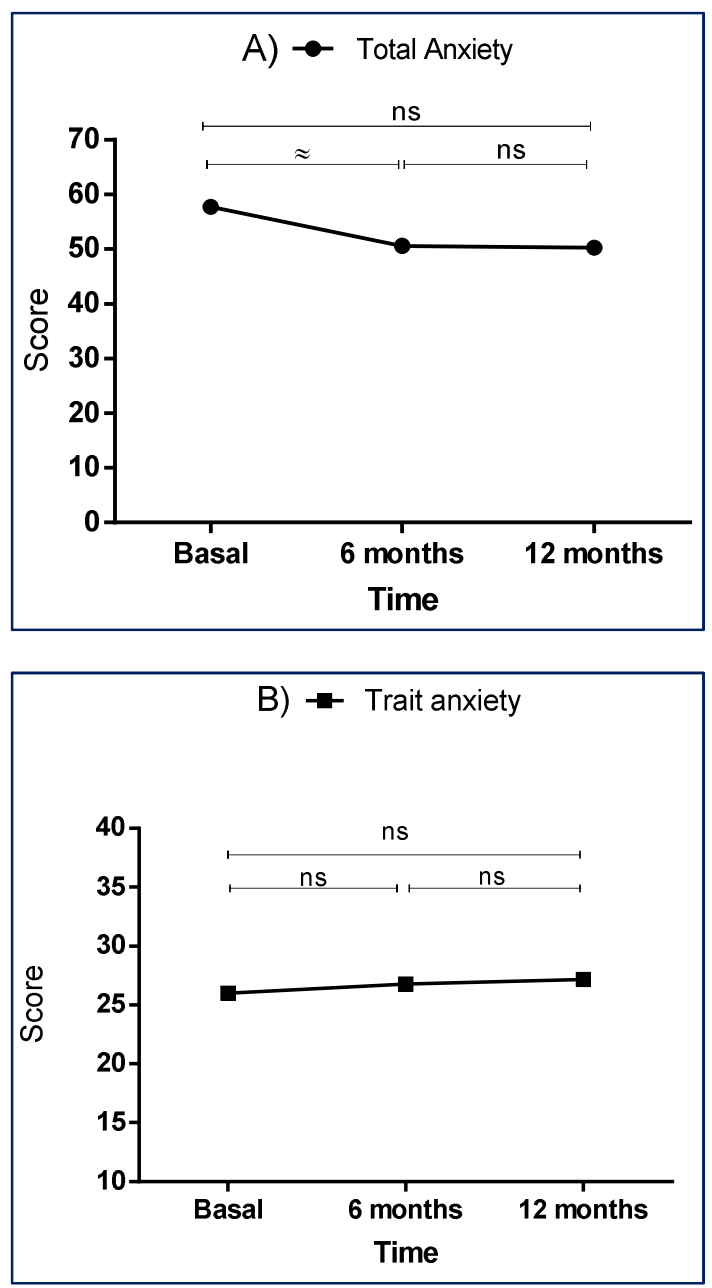
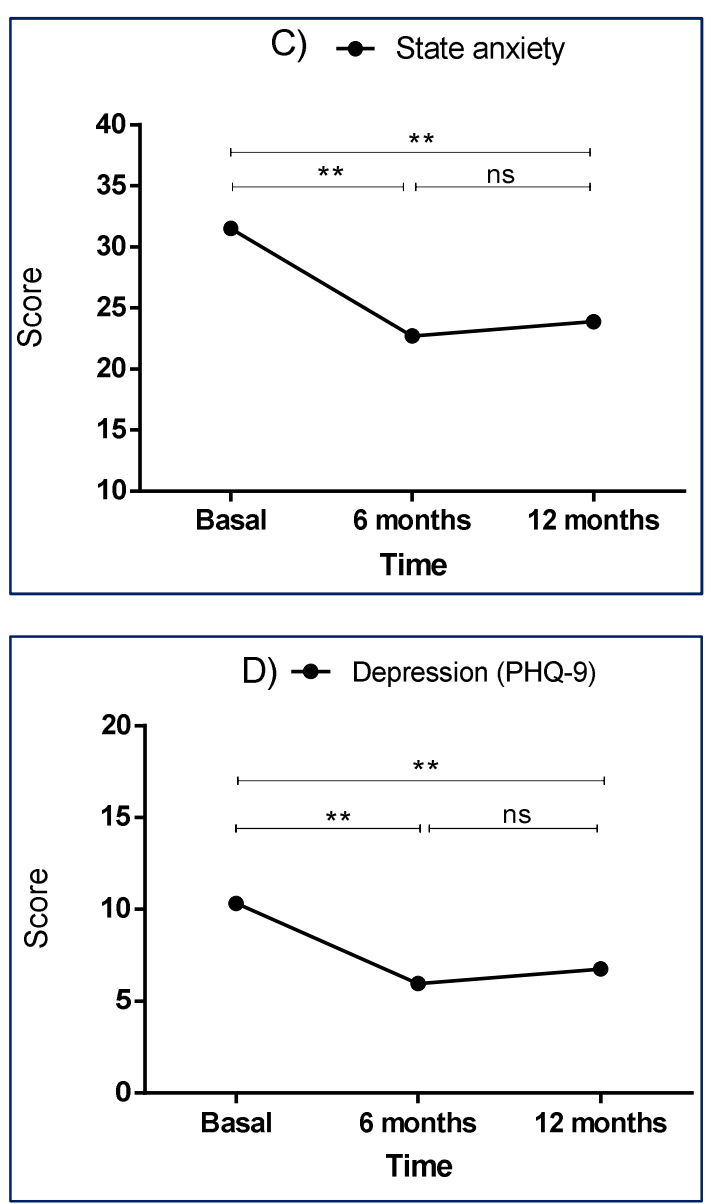

$\mathrm{p}=* \mathrm{p} \leq .05 * * \mathrm{p} \leq .01, * * * \mathrm{p} \leq .001, \mathrm{~ns}=$ non-significant

Figure 1. Comparison: Anxious symptomatology (A-total; B-trait; $C$-state) and Depressive symptoms (D) at Baseline, 6 and 12 months.

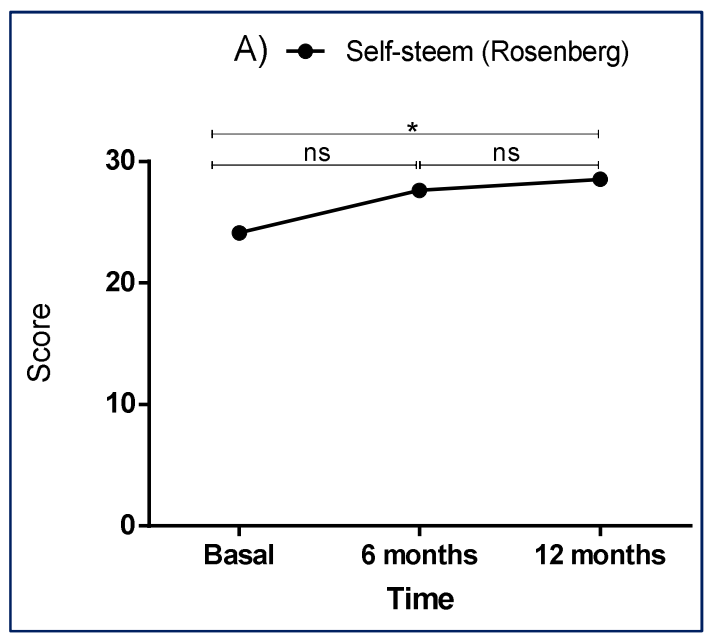



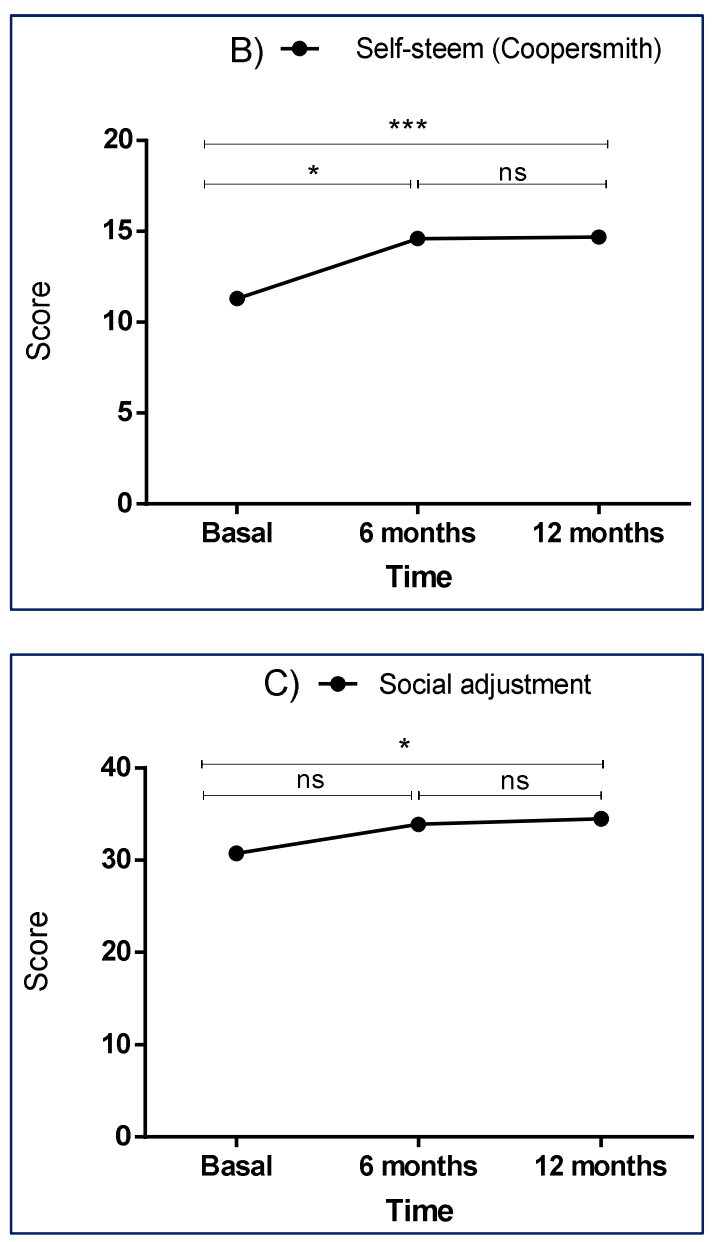

$* \mathrm{p} \leq .05 * * \mathrm{p} \leq .01, * * * \mathrm{p} \leq .001, \mathrm{~ns}=$ non-significant

Figure 2. Changes from baseline to 6 and 12 months in Self-esteem (A y B) and Social Adaptation (C).

On the other hand, aspects related to well-being seemed to show more evident changes until 12 months. As a result of this, self-esteem using Rosenberg scale showed variations over time $\left(F_{(2)}=4.95, \mathrm{p}=.012\right)$. The following analysis demonstrated that these changes were not found at 6 months $(p=.152)$, but until 12 months $(p=.005)$, without any variations between 6 and 12 months $(\mathrm{p}=.152)$ (Figure 2a).

Self-esteem according to Coopersmith Inventory also changed over time $F_{(2)}=8.11, \mathrm{p}=.001$, with variances at 6 months $(\mathrm{p}=.018)$, and at 12 months $(\mathrm{p}=.001)$, but not between 6 and 12 months $(\mathrm{p}=.999)$ (Figure 2b). Finally, social adaptation showed variations over time, $F_{(2)}=3.36, \mathrm{p}=.046$, but without any changes from baseline to 6 months, $(\mathrm{p}=.181)$ but until 12 months $(\mathrm{P}=.042)$ (Figure 2c).

When comparing pharmacological treatment, Anxietystate preserved its main effect $\left(F_{(2)}=8.71, \mathrm{p}=.001\right)$, without time-group interaction $\left(F_{(2)}=0.54, \quad \mathrm{p}=.947\right) ;$ depressive symptomatology preserved main effect $\left(F_{(2)}=12.40, \mathrm{p}=.0001\right)$ without time-group interactions $\left(F_{(2)}=0.67, \mathrm{p}=.518\right)$.

Rosenberg's self-esteem showed main effect $F_{(2)}=4.66$, $\mathrm{p}=.016$, but not time-group $F_{(2)}=1.31, \mathrm{p}=.282$. Coopersmith's self-esteem also kept its main effect $\left(F_{(2)}=8.55, \mathrm{p}=.001\right)$, without time-group interaction $\left(F_{(2)}=1.32, \quad \mathrm{p}=.279\right)$; nevertheless, social adaptation relatively preserved its main effect $F_{(2)}=2.56, \mathrm{p}=.092(\mathrm{p}=.097)$, but also without any interaction effect $F_{(2)}=0.31, \mathrm{p}=.732$.

Table 2 shows the correlations between symptoms' scales scores with the well-being aspects of the students. It is observed that, independently of time, self-esteem (Rosenberg and Coopersmith) significantly correlated to the decrease in most of the measures of anxiety-state, anxiety-trait, and depression over time. In the same way, the increase in the baseline social adjustment score was associated with a decrease in the baseline social anxiety score, and the social adjustment at 6 months with a decrease in the depression score at 12 months.

Table 2. Correlation of scale scores over time.

\begin{tabular}{|c|c|c|c|c|c|c|c|c|c|c|c|c|c|}
\hline & & \multicolumn{3}{|c|}{ Total Anxiety } & \multicolumn{3}{|c|}{ Anxiety State } & \multicolumn{3}{|c|}{ Anxiety Trait } & \multicolumn{3}{|c|}{ Depression } \\
\hline & & Base-line & $6 \mathrm{~m}$ & $12 \mathrm{~m}$ & Base-line & $6 \mathrm{~m}$ & $12 \mathrm{~m}$ & Base-line & $6 \mathrm{~m}$ & $12 \mathrm{~m}$ & Base-line & $6 \mathrm{~m}$ & $12 \mathrm{~m}$ \\
\hline \multirow{3}{*}{$\begin{array}{l}\text { Self-esteem } \\
\text { (Rosenberg) }\end{array}$} & Base-line & -.02 & -.07 & -.26 & -.27 & $-.37^{*}$ & -.14 & -.17 & -.27 & -.15 & $-.57^{* *}$ & -.27 & $-.42^{*}$ \\
\hline & $6 \mathrm{~m}$ & -.09 & -.04 & -.19 & $-.46^{* *}$ & $-.60^{* *}$ & $-.35^{*}$ & -.30 & -.21 & -.33 & -.22 & $-.54^{* *}$ & -.08 \\
\hline & $12 \mathrm{~m}$ & .05 & .06 & -.38 & $-.50^{*}$ & $-.49^{*}$ & $-.50^{*}$ & $-.73^{* *}$ & $-.54^{* *}$ & $-.70^{* *}$ & -.33 & -.23 & $-.62^{* *}$ \\
\hline \multirow{2}{*}{$\begin{array}{l}\text { Self-esteem } \\
\text { (Coopersmith) }\end{array}$} & Base-line & -.12 & -.11 & -.31 & -.23 & $-.41^{* *}$ & -.12 & -.32 & $-.57^{* *}$ & -.16 & $-.46^{* *}$ & $-.34^{*}$ & $-.52^{*}$ \\
\hline & $6 \mathrm{~m}$ & -.10 & -.15 & $-.32^{*}$ & $-.61^{* *}$ & $-.65^{* *}$ & $-.58^{* *}$ & $-.50^{*}$ & $-.64^{* *}$ & -.40 & -.30 & $-.54^{* *}$ & -.42 \\
\hline \multirow{3}{*}{ Social Adaptation } & Base-line & $.37^{*}$ & .19 & .23 & .04 & .10 & -.09 & -.00 & .12 & -.05 & -.13 & -.02 & -.12 \\
\hline & $6 \mathrm{~m}$ & .16 & .03 & -.02 & -.22 & -.16 & -.22 & -.08 & -.15 & -.03 & -.31 & -.02 & $-.42^{*}$ \\
\hline & $12 \mathrm{~m}$ & .20 & .10 & -.06 & -.31 & -.24 & -.30 & .03 & .05 & -.03 & .09 & .19 & .20 \\
\hline
\end{tabular}

$* \mathrm{p} \leq 0.05, * * \mathrm{p} \leq 0.01$

\section{Discussion}

Long-term group psychotherapy shows improvement on the different assessed parameters, although only 23 of the patients could be evaluated at 12 months, against 41 who stayed for six months. This desertion may be related to the change in their schedules, academic responsibilities or even that they finished their careers.

As the tables show, it may seem that the improvement at 12 months is not as remarkable as it is at 6 months; nevertheless, it continues with this tendency, without decreasing, which reflects that changes remain over time.

This kind of therapy improves personality and patterns of behavior as a result of the interaction with students that are 
going through the same problems (school, relationships or family problems), working collaboratively with each other and with the group leaders and obtaining feedback about the meaning and effect of their participation. It may also help students to deal with lack of confidence or lack of selfesteem by recognizing their weakness and strengths and exploring possible factors that trigger the negative selfconcept.

One of the strengths of group therapy is that it may be a useful option of treatment for patients in college psychiatricpsychological centers because they can also be seen in less time than in individual therapies, which may also require more personnel. It also offers a benefit-cost advantage since more patients can be seen in psychotherapy and more frequently, with the benefits of a long-term group interactional approach (therapeutic factors), in congruence with what has been pointed out in other studies [1].

The weakness of the trial is that it may be difficult to have a long-term control group without treatment because it is unethical. However, on future studies patients of group therapy could be compared to those who receive pharmacological treatment and monthly individual sessions, as in our Mental Health Department, where there is an over demand because of the large population it attends.

\section{Conclusions}

As a result of interactional therapy, positive changes were observed in the patients, demonstrating that this type of therapy is especially useful for the population attended in the clinic (mostly college students). Therefore, it not only helps to improve their functionality, depressive and anxious symptoms but also reinforces self-esteem and social adaptation, allowing these changes to remain over time.

\section{Conflicts of Interest}

All the authors do not have any possible conflicts of interest.

\section{References}

[1] Weatherford, R. D. "Estimating the Efficiency of Therapy Groups in a College Counseling Center". Journal of College Student Psychotherapy, 31 (3): 1-7, February 2017.

[2] Carlson, T. M. "A short-term dynamic psychotherapy approach for college students". Journal of College Student Psychotherapy, 18 (3), 47-67, 2004.

[3] Eisenberg, D., Gollust, S. E., Golberstein, E., \& Hefner, J. L. "Prevalence and correlates of depression, anxiety, and suicidality among university students." American Journal of Orthopsychiatry, 77 (4), 534-542, 2007.

[4] Ghodasara, S. L., Davidson, M. A., Reich, M. S., Savoie, C. V., \& Rodgers, S. M. "Assessing student mental health at the Vanderbilt University School of Medicine." Academic Medicine, 86 (1), 116-121, 2011.
[5] Garay, C. J., Korman, G. P., \& Keegan, E. "Terapia cognitivo conductual en formato grupal para trastornos de ansiedad y trastornos del estado de ánimo." Subjetividad y Procesos Cognitivos (12), 61-72, 2008.

[6] Ontario College Health Association. "Towards a comprehensive mental health strategy: The crucial role of colleges and universities as partners." December 2009. Available at: http://oucha.ca/mental_health.php. [Date of acces: October 2017]

[7] Leichsenring, F., \& Rabung, S. "Effectiveness of long-term psychodynamic psychotherapy: A meta-analysis". JAMA, 300 (13), 1551-1565, 2008.

[8] Shedler, J. "The efficacy of psychodynamic psychotherapy." Am Psychol, 65 (2), 98-109, 2010. doi: 10.1037/a0018378.

[9] Belló, M., Puentes-Rosas, E., \& Medina-Mora, M. E. "Prevalencia y diagnóstico de depresión en población adulta en México". Salud Pública de México, 47 (1), S4-S11, 2005.

[10] Rocha, H. M., \& Ortega-Soto, H. A. "La depresión en los estudiantes universitarios de la Escuela Nacional de Estudios Profesionales, Plantel Aragón”. Salud mental, 18 (2), 31-34, 1995.

[11] Balanza-Galindo, S., Morales-Moreno, I., \& Guerrero-Muñoz, J. (2009). Prevalencia de ansiedad y depresión en una población de estudiantes universitarios: factores académicos y sociofamiliares asociados. Clínica y Salud, 20 (2), 177-187.

[12] Riveros, M., Hernández, H., \& Rivera, J. "Niveles de depresión y ansiedad en estudiantes universitarios de Lima Metropolitana”. Revista de investigación en psicología, 10 (1), 91-102, 2007.

[13] Vázquez, F. L., Torres, Á. Otero, P., \& Díaz, O. "Prevalence, comorbidity, and correlates of DSM-IV axis I mental disorders among female university students". The Journal of nervous and mental disease, 199 (6), 379-383, 2011.

[14] World Health Organization."Promoting mental health: Concepts, emerging evidence, practice: Summary report. Herrman, H., Saxena, S., Moodie, R., \& World Health Organization." Promoting mental health: concepts, emerging evidence, practice: a report of the World Health Organization, Department of Mental Health and Substance Abuse in collaboration with the Victorian Health Promotion Foundation and the University of Melbourne, 2004.

[15] Mejías, J. A., Jurado, M. M., Winckelmann, R., \& Tafoya, S. A. "Evaluación del cambio en pacientes universitarios nohospitalizados bajo psicoterapia de grupo". CIMEL, 19 (2), 2014.

[16] Yalom, I. D., \& Valdés, C. Teoría y práctica de la psicoterapia de grupo. Fondo de Cultura Económica, México, 1986.

[17] MacKenzie, K. R., \& Livesley, W. J. "Outcome and process measures in brief group psychotherapy". Psychiatric Annals, 16 (12), 715-720, 1986.

[18] Shapiro, D., Caplan, H., Rohde, P., \& Watson, J. "Personal questionnaire changes and their correlates in a psychotherapeutic group". British Journal of Medical Psychology, 48 (3), 207-215, 1975.

[19] Dick, B. M., \& Wooff, K. "An evaluation of a time-limited programme of dynamic group psychotherapy". The British Journal of Psychiatry, 148 (2), 159-164, 1986. 
[20] Budman, S. H. "Discussion of" Peer relationships, self-esteem, and the self: Implications for the group therapist". International journal of group psychotherapy, 37 (4), 515-518, 1987.

[21] Soleymani M., Mohammad, K. P., \& Doulatshahi, B. "Effectiveness of brief group interpersonal psychotherapy in reducing university students' depressive symptoms and its effect on attributional style and dysfunctional attitudes". Psychological Research, 11 (1-2), 41-65, 2008.

[22] Arenas, I. A "Resultados de Psicoterapia Grupal Breve en Estudiantes Universitarios de la Quinta Región: Estudio Exploratorio Basado en Instrumentos Proyectivos". Terapia Psicológica, 23 (1), 37-47, 2005.

[23] Tillitski, C. J. "A meta-analysis of estimated effect sizes for group versus individual versus control treatments". International Journal of Group Psychotherapy, 40 (2), 215224, 1990.

[24] Yang, T. T., Hsiao, F. H., Wang, K. C., Ng, S. M., Ho, R. T., Chan, C. L., Chen, Y. T. "The effect of psychotherapy added to pharmacotherapy on cortisol responses in outpatients with major depressive disorder". The Journal of nervous and mental disease, 197 (6), 401-406, 2009.

[25] Baader, T., Molina, J. L., Venezian, S., Rojas, C., Farías, R., Fierro-Freixenet, C., Mundt, C. "Validación y utilidad de la encuesta PHQ-9 (Patient Health Questionnaire) en el diagnóstico de depresión en pacientes usuarios de atención primaria en Chile". Revista chilena de neuro-psiquiatría, 50 (1), 10-22, 2012.

[26] Löwe, B., Kroenke, K., Herzog, W., \& Gräfe, K. "Measuring depression outcome with a brief self-report instrument: sensitivity to change of the Patient Health Questionnaire (PHQ-9)". Journal of affective disorders, 81 (1), 61-66, 2004.

[27] Fonseca-Pedrero, E., Paino, M., Sierra-Baigrie, S., LemosGiráldez, S., \& Muñiz, J. "Propiedades psicométricas del Cuestionario de ansiedad estado-rasgo (STAI) en universitarios". Psicología Conductual, 20 (3), 547, 2012.

[28] Silva, C., Medina, A. H., Cruz, B. E. J., \& Alvarado, N. "Revisión de la estructura interna de la subescala de rasgo del Inventario de Ansiedad Rasgo-Estado para jóvenes de habla hispana". Psicología y Salud, 26 (2), 253-262, 2016.

[29] Barnes, L. L., Harp, D., \& Jung, W. S. "Reliability generalization of scores on the Spielberger state-trait anxiety inventory". Educational and Psychological Measurement, 62 (4), 603-618, 2002.

[30] Lara-Cantú, M. A., Verduzco, M. A., Acevedo, M., \& Cortés, J. "Validez y confiabilidad del Inventario de Autoestima de Coopersmith para adultos, en población mexicana". Revista Latinoamericana de Psicología, 25 (2), 247-255, 1993.

[31] González-Forteza, C. F., \& Ruiz, E. R. "Autoestima y sintomatología depresiva en adolescentes mexicanos: un estudio correlacional por género". Rev. ABP-APAL, 15 (2), 59-64, 1993.

[32] Bobes, J., González, M., Bascarán, M., Corominas, A., Adán, A., Sánchez, J., \& Such, P. "Validation of the Spanish version of the social adaptation scale in depressive patients". Actas espanolas de psiquiatria, 27 (2), 71-80, 1998.

[33] Mejías, J. A., Jurado, M. M., Tafoya, S. A, Romo F., Sandoval J. R., Beltrán L. "Effects of group psychotherapy on depressive and anxious symptoms, self-esteem and social adaptation in college students". Unpublished. 